Check for updates

Cite this: RSC Adv., 2017, 7, 32613

\title{
Nanoparticles co-delivering pVSVMP and pIL12 for synergistic gene therapy of colon cancer
}

\author{
Yuanyuan Xiao, (D) $\dagger^{\mathrm{a}}$ Yuping Yang, $\uparrow^{\mathrm{a}}$ Yujiao Wu, $\uparrow^{\mathrm{a}}$ Chunmei Wang, (D) a Hao Cheng, ${ }^{\mathrm{a}}$ \\ Wei Zhao, (D) ab Yang Li, ${ }^{a}$ Beibei Liu, ${ }^{a}$ Jianlin Long, (D) acd Wenhao Guo, ${ }^{\text {ae }}$ \\ Guangping $\mathrm{Gao}^{\mathrm{a}}$ and Maling Gou*a
}

Nanoparticles delivering therapeutic genes have promising applications in cancer treatments. Here, we used biodegradable heparin-polyethyleneimine (HPEI) nanoparticles to co-deliver two genes (vesicular stomatitis virus matrix protein, VSVMP; interleukin-12, IL12) for cancer therapy. These HPEI nanoparticles can bind the plasmid expressing VSVMP (pVSVMP) and the plasmid expressing IL12 (pIL12) through electrostatic interactions, and mediate the simultaneous expression of VSVMP and IL12 in colon cancer cells in vitro and in vivo. After intraperitoneal administration, the HPEI/pIL12 + pVSVMP complexes efficiently inhibit the growth of intraperitoneal metastasis of C-26 colon cancer, showing synergistic anticancer efficacy, without obvious systemic adverse effects. While VSVMP induces apoptosis, VSVMP and IL12 synergistically generate an anticancer immune response, which renders the potent anticancer effect of HPEI/pIL12 + pVSVMP. Our data suggest that VSVMP and IL12 could synergistically inhibit cancer survival in vivo, and the HPEI nanoparticle co-delivered VSVMP and IL12 might have potential application in treating intraperitoneal metastasis of colon cancer.

Received 31st March 2017

Accepted 2nd June 2017

DOI: $10.1039 / c 7 r a 03727 a$

rsc.li/rsc-advances clinical trials worldwide in gene therapy have been aimed at the treatment of various types of solid or hematological malignancies. ${ }^{13}$ The vesicular stomatitis virus matrix protein (VSVMP) from vesicular stomatitis virus (VSV) causes apoptosis of cells by inhibiting host gene expression and disorganizing cytoskeletal elements. ${ }^{14-16}$ Previous studies in our laboratory have demonstrated that gene therapy with VSVMP alone or combined with chemotherapy efficiently inhibit the growth of solid tumor and significantly prolong the survival time. VSVMP could directly induce tumor cell apoptosis, its antitumor effect was also accompanied by cytotoxic T lymphocytes (CTLs) and NK cells activation. ${ }^{17-23}$ During the past two decades, a great number of researches have demonstrated that gene therapy with IL12 has a potent anticancer activity in various tumor models. ${ }^{24-26}$ IL12, as a heterodimeric pro-inflammatory cytokine, could activate both innate and adaptive immunities and induce the production of interferon gamma $(\operatorname{IFN}-\gamma){ }^{24,27,28}$ In this regard, we wonder whether gene therapy with IL12, which is capable of activating immune effector cells, could enhance the antitumor effects of VSVMP.

Recently, both viral vectors and non-viral vectors have been investigated as delivery vehicles in cancer gene therapy. Compared with viral vectors, non-viral vectors are demonstrated to show several important safety advantages, such as reduced pathogenicity, absence of risk of transgenes insertional mutagenesis, low immune-toxicity, handy chemical modification, low cost and simply production..$^{29}$ Non-viral vectors, such as polyethyleneimine (PEI), due to its strong condensation of DNA, 
which further facilitates endocytosis and prevents the DNA degradation from the endosomal disruption, has been widely investigated and applied as a gene delivery vehicle. ${ }^{30,31}$ However, PEI still have some disadvantages, such as cytotoxicity and nonbiodegradability, ${ }^{32,33}$ and several strategies have been investigated to modify PEI to address these issues. ${ }^{34-36}$ Our previous studies have demonstrated that heparin-polyethyleneimine (HPEI) nanoparticles, which were prepared by covalently conjugating low molecular weight PEI2K with heparin, could efficiently and safely deliver gene into cells, overcoming the limitations of PEI such as the high cytotoxicity and non-biodegradability. ${ }^{23,37,38}$ Simultaneous delivery of multiple therapeutic candidates via nanoparticles is a promising choice for the treatment of cancer. ${ }^{39-43}$ Here we try to use the biodegradable HPEI nanoparticles to co-deliver PVSVMP and pIL12. Our hypothesis is that, co-delivery of VSVMP and IL12 by HPEI nanoparticles could show the synergistic effect and perform excellent inhibition of colon cancer.

In the present study, HPEI nanoparticles as synergistic combinational delivery vehicles were prepared and then electrostatically complexed with pVSVMP and pIL12 to form the HPEI/pIL12 + pVSVMP complexes. The physicochemical properties of the complexes (i.e. especially size, zeta-potential, gel retardation and morphology) were characterized. This HPEI nanoparticle could efficiently bind pVSVMP and pIL12 through electrostatic interaction, and mediate the simultaneous expression of VSVMP and IL12 in colon cancer cells in vitro and in vivo. To further study the combinatory therapy effects of HPEI/pIL12 + pVSVMP complexes, the anticancer activities of HPEI/pIL12 + pVSVMP complexes were investigated. The synergistic mechanisms were studied by using TUNEL assay,
$\mathrm{Ki}_{67}$ staining and flow cytometry assay. Our results suggested that the synergistic antitumor effect of HPEI/pIL12 + pVSVMP complexes may result from induction of cancer cell apoptosis, inhibition of tumor cell proliferation and activation of immune effector cells (Fig. 1).

\section{Materials and methods}

\section{Materials}

Poly-ethyleneimine (molecular weight 2000 [PEI2K]), 2-(Nmorpholino)ethane-sulfonic acid (MES), 1-ethyl-3-(3-dimethylaminopropyl)carbodiimide (EDC), $N$-hydroxysuccinimide (NHS), and 3-(4,5-dimethylthiazol-2-yl)-2,5-diphenyl tetrazolium bromide (MTT) were purchased from Sigma (St Louis, MO, USA). Dulbecco's Modified Eagle's Medium (DMEM), fetal bovine serum (FBS), penicillin, and streptomycin were purchased from HyClone ${ }^{\mathrm{TM}}$ (GE Healthcare UK Ltd, Little Chalfont, UK). DNA ladder was provided by Fermentas (Thermo Fisher Scientific Inc., Waltham, MA, USA). Balb/c mice (6-8 weeks old) were obtained from the Beijing HFK Bioscience (Beijing, China). All animal procedures were performed according to the guidelines of Sichuan University and approved by the Animal Care Committee of Sichuan University (Chengdu, China).

\section{Construction and purification of plasmid-based expression vectors: pVSVMP and pIL12}

VSVMP was inserted into the pVAX plasmid at a BamHI site and a EcoRI site forming the expression plasmid (pVSVMP). The plasmid (pIL12) encoding p35 and p40 subunits of murine IL12

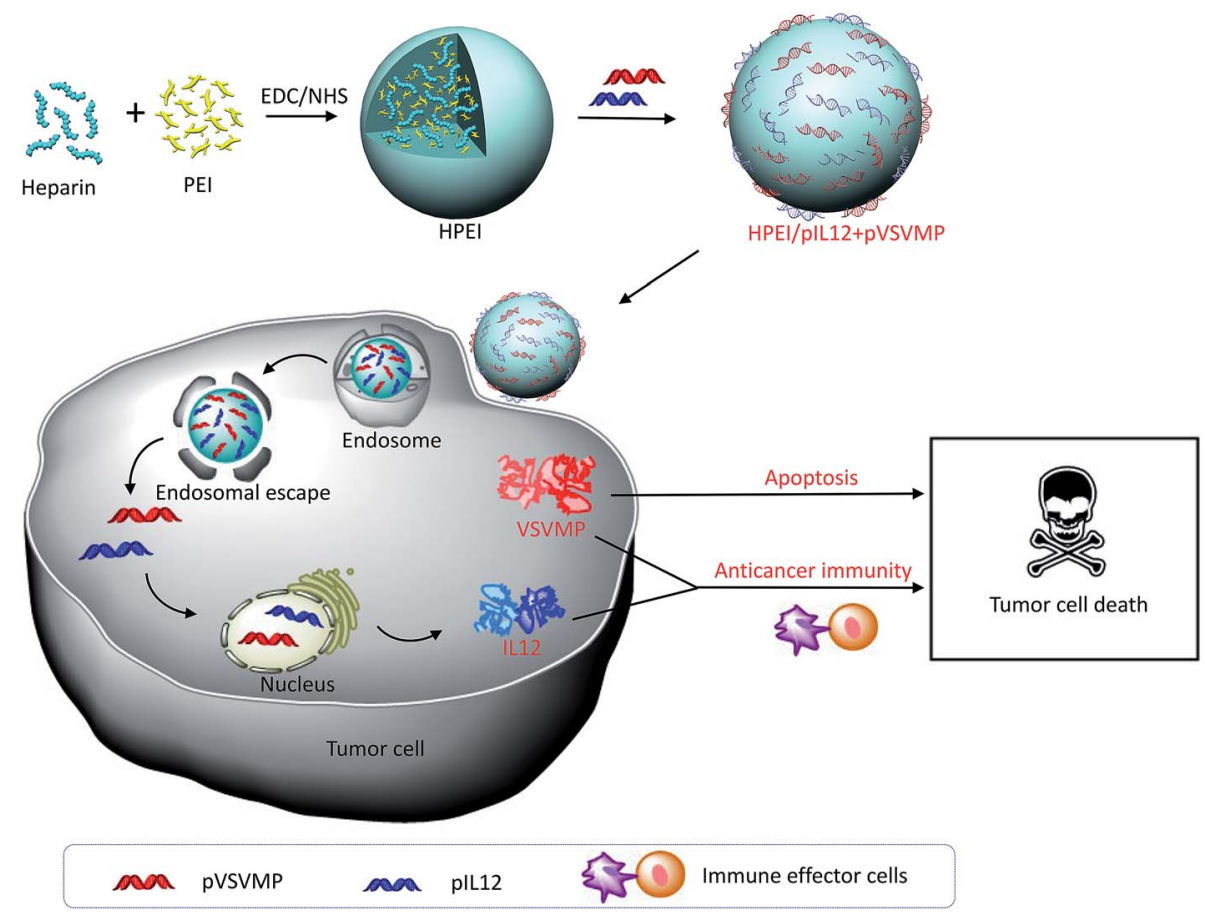

Fig. 1 Schematic illustration of co-delivered pIL12 and pVSVMP by HPEI nanoparticle for improving anticancer efficacy by synergistic therapeutic effects. 
was constructed at the BamHI site and the XhoI site of the pVAX vector (Invitrogen, San Diego, CA, U.S.). The empty plasmid pVAX was used as negative control (pEP). The recombinant plasmid and negative control plasmid were prepared using the Endofree Plasmid kit (Omega Bio-Tek, Norcross, GA, USA) in accordance with the manufacturer's instructions. Escherichia coli colonies were cultured in Luria-Bertani broth with kanamycin $\left(50 \mu \mathrm{g} \mathrm{mL}^{-1}\right)$.

\section{Preparation and characterization of HPEI nanoparticles}

HPEI nanoparticles were prepared as described previously. ${ }^{23,44}$ Briefly, $50 \mathrm{mg}$ of heparin was dissolved in a MES buffer solution $(100 \mathrm{~mL}, 0.05 \mathrm{M})$; then, $30 \mathrm{mg}$ of NHS and $20 \mathrm{mg}$ of EDC were added into the aforementioned solution to activate the carboxylic acid groups of heparin. After $2 \mathrm{~h}$ of reaction, this solution was dropped into $20 \mathrm{~mL}$ of PEI2K solution $(7.5 \mathrm{mg}$ $\mathrm{mL}^{-1}$ ) while stirring consistently at room temperature overnight. Later the obtained HPEI nanoparticles were dialyzed (molecular weight cut off $=8000-14000$ ) in distilled water for 3 days. Then, the HPEI nanoparticles were filtered by using a syringe filter (pore size $=220 \mathrm{~nm}$ ) (Millex-LG; EMD Millipore, Billerica, MA, USA). The HPEI nanoparticles were adjusted to $1 \mathrm{mg} \mathrm{mL}{ }^{-1}$ and stored at $4{ }^{\circ} \mathrm{C}$. The morphology of the HPEI nanoparticles was observed under a transmission electron microscope (TEM) (H-6009IV; Hitachi Ltd., Tokyo, Japan). The HPEI nanoparticles were diluted with distilled water and placed on a copper grid covered with nitrocellulose. The size and zeta potential of the HPEI nanoparticles or HPEI/pIL12 + pVSVMP complexes were determined by dynamic light scattering (Nano$\mathrm{ZS}$; Malvern Instruments, Malvern, UK) at $25^{\circ} \mathrm{C}$. All results were obtained as the mean of three test runs.

\section{Gel retardation assay}

The HPEI/DNA complexes were incubated at room temperature for $30 \mathrm{~min}$ and then electrophoresed on $1 \%(\mathrm{w} / \mathrm{v})$ agarose gel (Thermo Fisher Scientific) for $30 \mathrm{~min}$ at $100 \mathrm{~V}$. The agarose gel was dissolved in TAE buffer $(40 \mathrm{mM}$ Tris/ $\mathrm{HCl}, 1 \%$ acetic acid, $1 \mathrm{mM}$ ethylene diamine tetra-acetic acid, $\mathrm{pH}$ 7.4) and stained with Golden View ${ }^{\mathrm{TM}}$. The electrophoresis gels were illuminated by using a gel documentation system (Gel Doc 1000; Bio-Rad Laboratories Inc., Hercules, CA, USA).

\section{In vitro gene transfection}

C-26 cells were seeded into 6-well plates (Corning Incorporated, Corning, NY, USA) at a density of $2 \times 10^{5}$ cells per well in $2 \mathrm{~mL}$ of complete DMEM medium. After $24 \mathrm{~h}$ incubation, the medium was replaced with $800 \mu \mathrm{L}$ serum-free DMEM medium per well. pGFP as a report gene was added at $2 \mu \mathrm{g}$ per well, while the mass ratio of HPEI/pGFP and PEI25K/pGFP was 5/1, 1/1 respectively. After $6 \mathrm{~h}$ incubation, the medium was replaced by complete DMEM medium. $24 \mathrm{~h}$ later, the expression of green fluorescent protein (GFP) was observed by an Olympus IX 71 inverted fluorescence microscope (Olympus Corporation, Tokyo, Japan), and the transfection efficiency was recorded by flow cytometry (Epics Elite ESP, USA).

\section{Cytotoxicity assay}

The cytotoxicity of HPEI nanoparticles on the C-26 cells was measured by using MTT assay. In those tests, C-26 cells were plated at a density of $5 \times 10^{3}$ cells per well in $100 \mu \mathrm{L}$ of DMEM medium in 96-well plates. $24 \mathrm{~h}$ later, the cells were treated with different concentrations of HPEI nanoparticles or PEI25K for $48 \mathrm{~h}$. Subsequently, $10 \mu \mathrm{L}$ of $5 \mathrm{mg} \mathrm{mL}{ }^{-1}$ concentration of MTT reagent was added to each well and incubated at $37^{\circ} \mathrm{C}$ for $3 \mathrm{~h}$ in the dark until the purple formazan crystal was visible. Dimethyl sulfoxide (DMSO, $150 \mu \mathrm{L}$ ) was add to each well and cells were gently shaken for about $30 \mathrm{~min}$ in order to dissolve the formazan product. A microplate reader was used to measure the absorbance value of each well at a wavelength of $540 \mathrm{~nm}$. The relative cell viability was expressed as a percentage relative to the untreated control wells. Experiments were performed three times independently.

\section{Anticancer activity of HPEI/pIL12 + pVSVMP complexes on C- 26 cells in vitro}

C-26 cells were plated in 96-well plates at a density of $5 \times 10^{3}$ cells per well in $100 \mu \mathrm{L}$ of DMEM medium and incubated for $24 \mathrm{~h}$. Normal saline (NS) and HPEI nanoparticles were used as controls. HPEI/pEP complexes, HPEI/pIL12 complexes, HPEI/ pVSVMP complexes, or HPEI/pIL12 + pVSVMP complexes (5 $\mu \mathrm{g}$ HPEI/1 $\mu \mathrm{g}$ DNA) were prepared in DMEM medium without serum. The cells were then treated with those samples separately for $48 \mathrm{~h}$. The viability of cells was evaluated by MTT assays.

Furthermore, the apoptosis induction by HPEI/pIL12 + pVSVMP complexes were investigated in vitro. C-26 cells were plated in 6-well plates at a density of $2 \times 10^{5}$ cells per well in 2 $\mathrm{mL}$ of complete DMEM medium and incubated with NS, HPEI nanoparticles (10 $\mu \mathrm{g}$ HPEI), HPEI/pEP complexes $(10 \mu \mathrm{g}$ HPEI/2 $\mu \mathrm{g}$ DNA), HPEI/pIL12 complexes (10 $\mu \mathrm{g}$ HPEI/2 $\mu \mathrm{g}$ DNA), HPEI/ pVSVMP complexes (10 $\mu \mathrm{g}$ HPEI/2 $\mu \mathrm{g}$ DNA) or HPEI/pIL12 + pVSVMP complexes $(10 \mu \mathrm{g}$ HPEI/1 $\mu \mathrm{g}+1 \mu \mathrm{g}$ DNA) separately. After $6 \mathrm{~h}$ incubation, the medium was replaced by completed medium. $48 \mathrm{~h}$ later, apoptosis was examined by flow cytometric analysis using propidium iodide and annexin- $\mathrm{V}$ staining method.

\section{Murine colon cancer model}

Tumor models were established by intraperitoneal (i.p.) injection of C- 26 cells (about $5 \times 10^{5}$ cells $/ 200 \mu \mathrm{L}$ serum-free DMEM) into Balb/c mice on day 0 . Three days after inoculation, mice were randomly divided into five groups, and were then intraperitoneally injected with 7 dosages of NS, HPEI/pEP complexes (25 $\mu \mathrm{g} / 5 \mu \mathrm{g}), \mathrm{HPEI} / \mathrm{pIL} 12$ complexes $(25 \mu \mathrm{g} / 5 \mu \mathrm{g})$, HPEI/pVSVMP complexes $(25 \mu \mathrm{g} / 5 \mu \mathrm{g}), \mathrm{HPEI} / \mathrm{pIL} 12+$ pVSVMP complexes $(25$ $\mu \mathrm{g} / 2.5 \mu \mathrm{g}+2.5 \mu \mathrm{g})$ once every two days. The weights of mice were recorded every day. All mice were sacrificed by cervical vertebra dislocation on day 17, tumor weight, ascites volume and number of nodules were recorded and analyzed. Vital organs and tumors were obtained and fixed in $4 \%$ paraformaldehyde or frozen in liquid nitrogen immediately. The ascites was collected 
for the ELISA analysis. The anticancer effects were determined by tumor weight, ascites volume and tumor nodule numbers.

\section{Enzyme linked immunosorbent assay (ELISA)}

About $48 \mathrm{~h}$ after C-26 cells transfection with NS, HPEI nanoparticles, HPEI/pEP complexes, HPEI/pIL12 complexes, HPEI/ pVSVMP complexes or HPEI/pIL12 + pVSVMP complexes, the cell culture supernatants of each group were collected for IL12p70 ELISA analysis (eBioscience, Inc., San Diego, CA, U.S.). The expression of IL12 in tumors from mouse models were detected by IL12p70 ELISA analysis. The level of secreted IFN- $\gamma$ in tumors and ascites were also determined using commercially IFN- $\gamma$ ELISA kits (eBioscience, Inc., San Diego, CA, U.S.). For tumor samples, the tumors were first removed and weighted, and then were cut into pieces and homogenized. The whole process was performed on ice. The homogenized supernatants were subsequently collected by centrifuging for $10 \mathrm{~min}$ at $10000 \mathrm{rpm}$ at $4{ }^{\circ} \mathrm{C}$. All the ELISA assays were performed in accordance with the manufacturer's instructions.

\section{Real-time PCR}

Total RNA was isolated from cells and tumor tissues by using an RNA simple Total RNA Kit (TIANGEN, Beijing, China), and was then reverse-transcribed by using a PrimeScript ${ }^{\mathrm{TM}} \mathrm{RT}$ reagent Kit with gDNA Eraser (TaKaRa, Liaoning, China). The amount of cDNA used as templates was normalized to $\beta$-actin. The following sets of primers were used: VSVMP: forward, $5^{\prime}$-CGC GGA TCC ATC ATG AGT TCC TTA AAG AAG-3', reverse, $5^{\prime}$-CGG AAT TCT CAT TTG AAG TGG CTG ATA GAA TCC-3'; IL12p40: forward, 5'-AAC CTC ACC TGT ACA CGC C-3' ${ }^{\prime}$, reverse, 5'-CAA
GTC CAT GTT TCT TTG CAC G-3'; IFN- $\gamma$ : forward, $5^{\prime}$-TCA GCA ACA GCA AGG CGA AA-3', reverse, 5'-CCG CTT CCT GAG GCT GGA T-3'; $\beta$-actin, forward, $5^{\prime}$-AGA GCT ACG AGC TGC CTG AC$3^{\prime}$, reverse, 5'-AGC ACT GTG TTG GCG TAC AG-3'. The RT-PCR conditions comprised a 30 second step at $95{ }^{\circ} \mathrm{C}$, followed by $95{ }^{\circ} \mathrm{C}$ for 5 seconds and $56^{\circ} \mathrm{C}$ for 20 seconds for 39 cycles with melting curve analysis. Relative quantification of each gene was calculated after normalization to $\beta$-actin.

\section{Western blot analysis}

Protein concentrations of tumor lysates and the transfected cells were quantified with bicinchoninic acid assay protein assay kit (Bio-Rad Laboratories Inc.). Proteins from each sample were loaded into $10 \%$ sodium dodecyl sulphate-polyacrylamide gel electrophoresis and transferred to Millipore PVDF membranes. The membranes were blocked with $5 \%$ nonfat dried milk and incubated with anti-VSVMP (Chengdu Zen Bioscience Co., Ltd., Chengdu, Sichuan, China) or anti- $\beta$-actin (Santa Cruz Biotechnology Inc., Dallas, TX, USA) primary antibody at $4{ }^{\circ} \mathrm{C}$ overnight. The membranes were further incubated with corresponding secondary antibody conjugated with horseradish peroxidase (HRP) and developed with an enhanced chemiluminescence detection reagents (EMD Millipore, Billerica, MA, USA).

\section{Flow cytometric analysis}

For the analysis of lymphocytes infiltration in tumor tissues. Specimens of about $1 \mathrm{mg}$ of tumor tissue were taken from the NS, HPEI/pEP complexes, HPEI/pIL12 complexes, HPEI/ pVSVMP complexes or and HPEI/pIL12 + pVSVMP complexes
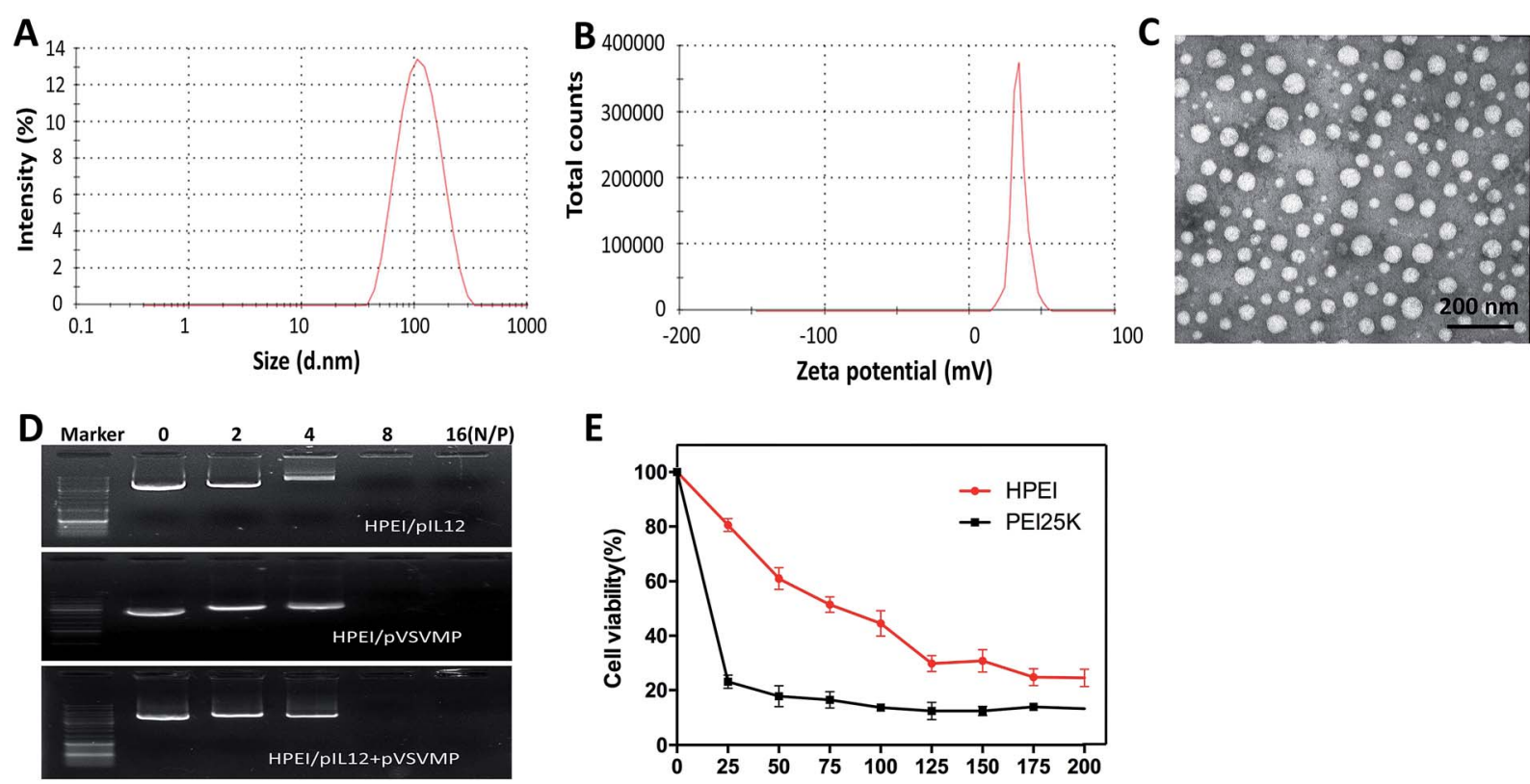

E

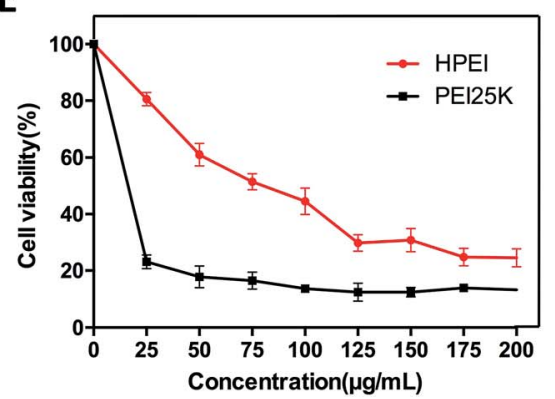

Fig. 2 Characterization of HPEI/pIL12 + pVSVMP complexes. (A) Size distribution spectrum of HPEI/pIL12 + pVSVMP complexes. (B) Zeta potential spectrum of HPEI/pIL12 + pVSVMP complexes. (C) Transmission electron microscopic image of HPEI/pIL12 + pVSVMP complexes. (D) The ability of HPEI nanoparticles binding plasmids determined by gel retardation assay. (E) C-26 cells were treated with PEI $25 \mathrm{~K}$ or HPEl in various concentrations, cell viability was measured by MTT assay. 
groups and digested into single-cell suspensions, then stained with FITC-CD3 and PE-CD8 antibodies for $30 \mathrm{~min}$ on ice. Mouse spleens from each group were harvested and filtrated with cell strainer $(74 \mu \mathrm{m})$ to form a single cell suspension. The single cells of each group were stained with PE-CD107a $\left(10 \mu \mathrm{L} \mathrm{mL}^{-1}\right)$ in the presence of interleukin-2 $\left(100 \mathrm{U} \mathrm{mL}^{-1}\right)$ and monensin for $4 \mathrm{~h}$ at $37^{\circ} \mathrm{C}$. Phorbol-12-myristate-13-acetate (PMA, $2.5 \mu \mathrm{g} \mathrm{mL}{ }^{-1}$; Sigma Chem. Co., St. Louis, MO, US) and ionophore (Ionomycin, $0.5 \mu \mathrm{g} \mathrm{mL}{ }^{-1}$; Sigma Chem. Co., St. Louis, MO, US) were used as positive controls. Cells were then stained with FITC$\mathrm{CD} 49 \mathrm{~b}$ for $30 \mathrm{~min}$ at $4{ }^{\circ} \mathrm{C}$. All the antibodies were purchased from BD biosciences. The analysis was performed on a FACS Calibur flow cytometer (BD Biosciences, San Jose, CA, U.S.) and data were analyzed by FlowJo software.

\section{TUNEL assay, immunohistochemistry and H\&E staining}

Tissues were fixed in $4 \%$ paraformaldehyde solution for more than $24 \mathrm{~h}$, then hydrated and embedded in paraffin blocks. The embedded tissues were sliced $(3-4 \mu \mathrm{m})$ and stained with hematoxylin and eosin. Immunohistochemical analysis of $\mathrm{Ki}_{67}$ antigen was carried out with rabbit anti-human $\mathrm{Ki}_{67}$ antibody (Novus Biologicals, Littleton, CO, US) using the labeled streptavidin-biotin method as previously described. ${ }^{45} \mathrm{Ki}_{67}$ expression was quantified by calculating the number of positive cells/total number of cells in five randomly selected areas at a $200 \times$ magnification. A commercially available terminal deoxynucleotidyl transferase-mediated nick end labeling (TUNEL) immunofluorescence kit (Promega, Madison, WI, U.S.) was used to examine the incidence of apoptosis in each group following the manufacturer's instructions. TUNEL positive cells were assessed by counting the apoptotic cells under a fluorescence microscope (Leica Microsystems CMS GmbH, Wetzlar, Germany) at a $200 \times$ magnification in randomly selected areas.

\section{Safety evaluation}

To evaluate the potential administration side effects and toxicity, relevant indices such as weight, diarrhea, appearance, skin ulcerations and toxic deaths were observed. Vital organs
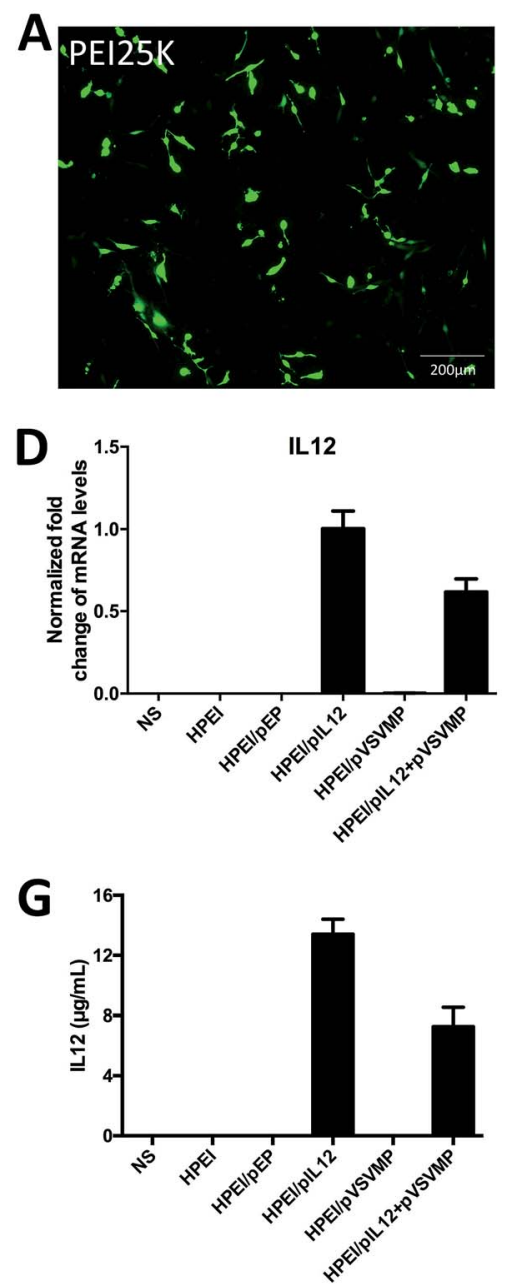
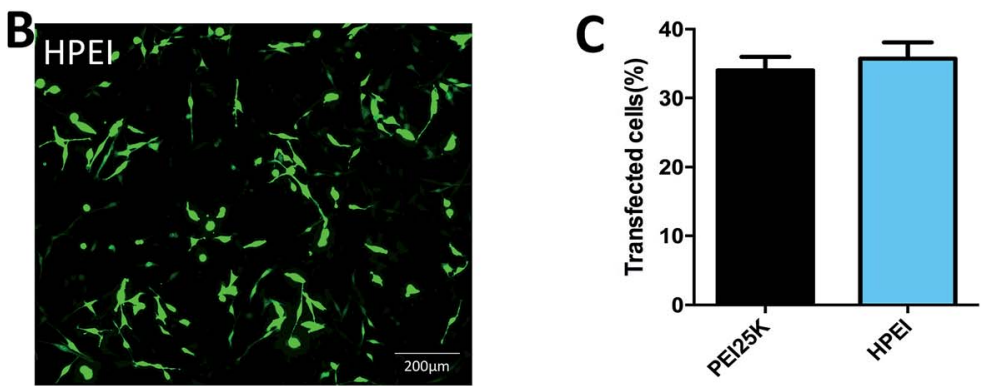

E

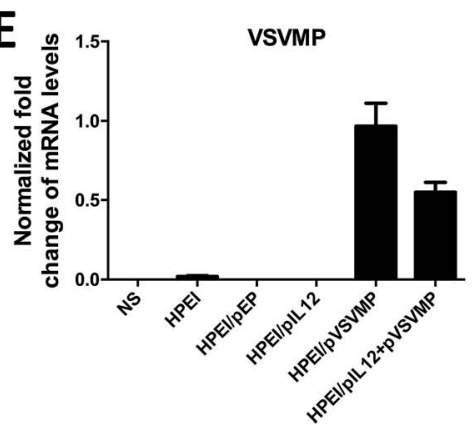

H

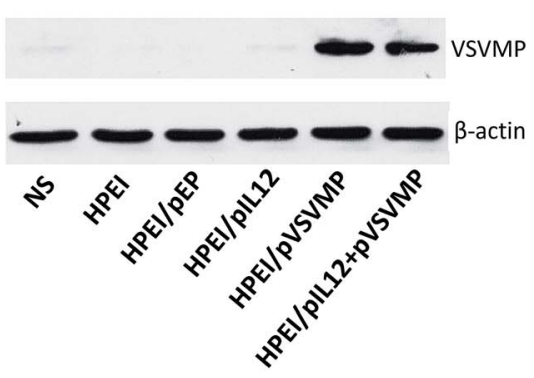

Fig. 3 Gene expression mediated by HPEI nanoparticles in vitro. (A) Fluorescent image of C-26 cells transfected by PEI25K/pGFP. (B) Fluorescent image of C-26 cells transfected by HPEI/pGFP. (C) The transfection efficiency of HPEI and PEI25K were determined by flow cytometry. (D, E and F) $48 \mathrm{~h}$ after C-26 cells transfected with HPEI/pIL12 + pVSVMP, the expression of IL12 and VSVMP were determined by RT-PCR. (G) Expression of IL12 examined by ELISA assay. (H) Expression of VSVMP at the protein expression level was determined by western blot analysis. 
(heart, liver, spleen, lung, and kidney) were harvested and stained with H\&E using standard methods.

\section{Results and discussion}

\section{Preparation and characterization of HPEI/pIL12 + pVSVMP complexes}

To efficiently deliver gene into tumor cell, the biodegradable cationic HPEI nanoparticles were prepared through amide bond heparin conjugated PEI molecules. The schematic representation of the preparation of HPEI/pIL12 + pVSVMP complexes was exhibited in Fig. 1. The particle size distribution spectrum of HPEI/pIL12 + pVSVMP complexes was presented in Fig. 2A, it was indicated that the complexes had a mean particle size of $101 \mathrm{~nm}$. As shown in Fig. 2B, the HPEI/pIL12 + pVSVMP complexes had a zeta potential of $35 \mathrm{mV}$. In addition, the transmission electron microscopy (TEM) image of HPEI/pIL12 + pVSVMP complexes indicated that those complexes were monodisperse and had the mean particle size of $53 \mathrm{~nm}$ (shown in Fig. 2C).

Gel retardation assays were used to evaluate the ability of the HPEI nanoparticles that bound to PIL12 and pVSVMP. As shown in Fig. 2D, the HPEI nanoparticles with positive charges could efficiently bind to negative plasmids. When the $\mathrm{N} / \mathrm{P}$ ratio of HPEI to DNA was $\geq 8$, a complete retardation of DNA was achieved, no other band of free DNA was observed on the gel. This suggested that the anionic pVSVMP and pIL12 were completely absorbed on the surface of HPEI nanoparticles due to electrostatic interaction, forming HPEI/pIL12 + pVSVMP complexes.

Then, we compared the cytotoxicity and transfection efficiency of HPEI nanoparticles with PEI25K (as a standard transfection agent) in vitro. MTT assay revealed that, at a concentration of $25 \mu \mathrm{g} \mathrm{mL} \mathrm{m}^{-1}$, PEI25K could significantly inhibit the growth of C-26 cells, showing an obvious toxicity, while HPEI nanoparticles had much less toxicity, the results were presented in Fig. 2E. The transfection efficiency of HPEI nanoparticles and PEI25K in C-26 cells were determined by flow cytometry, the results showed that the transfection efficiency of HPEI nanoparticles was $35.7 \pm 2.3 \%$, while the transfection efficiency of PEI25K was $34.1 \pm 1.9 \%$ (Fig. 3A-C). The transfection efficiency of HPEI nanoparticles on the C-26 cells is comparable to that of PEI25K $(p=0.29)$ and with less cytotoxicity than PEI25K. Those results are consistent with previous reports that HPEI could efficiently carry DNA with low cytotoxicity, ${ }^{23,44}$ showing great promising as gene co-delivery vehicles.

\section{Anticancer activity of HPEI/pIL12 + pVSVMP complexes in vitro}

To evaluate the anticancer activity of HPEI/pIL12 + pVSVMP complexes on the $\mathrm{C}-26$ cell line. We firstly measured the expression of DNA plasmids in C-26 cell line by RT-PCR, ELISA and western blot analysis. $48 \mathrm{~h}$ after transfection, the expression of IL12 could be detected in HPEI/pIL12 complexes group and HPEI/pIL12 + pVSVMP complexes group (Fig. 3D, F and G).

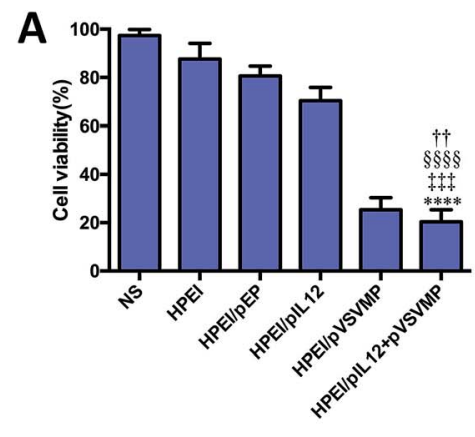

\section{B}
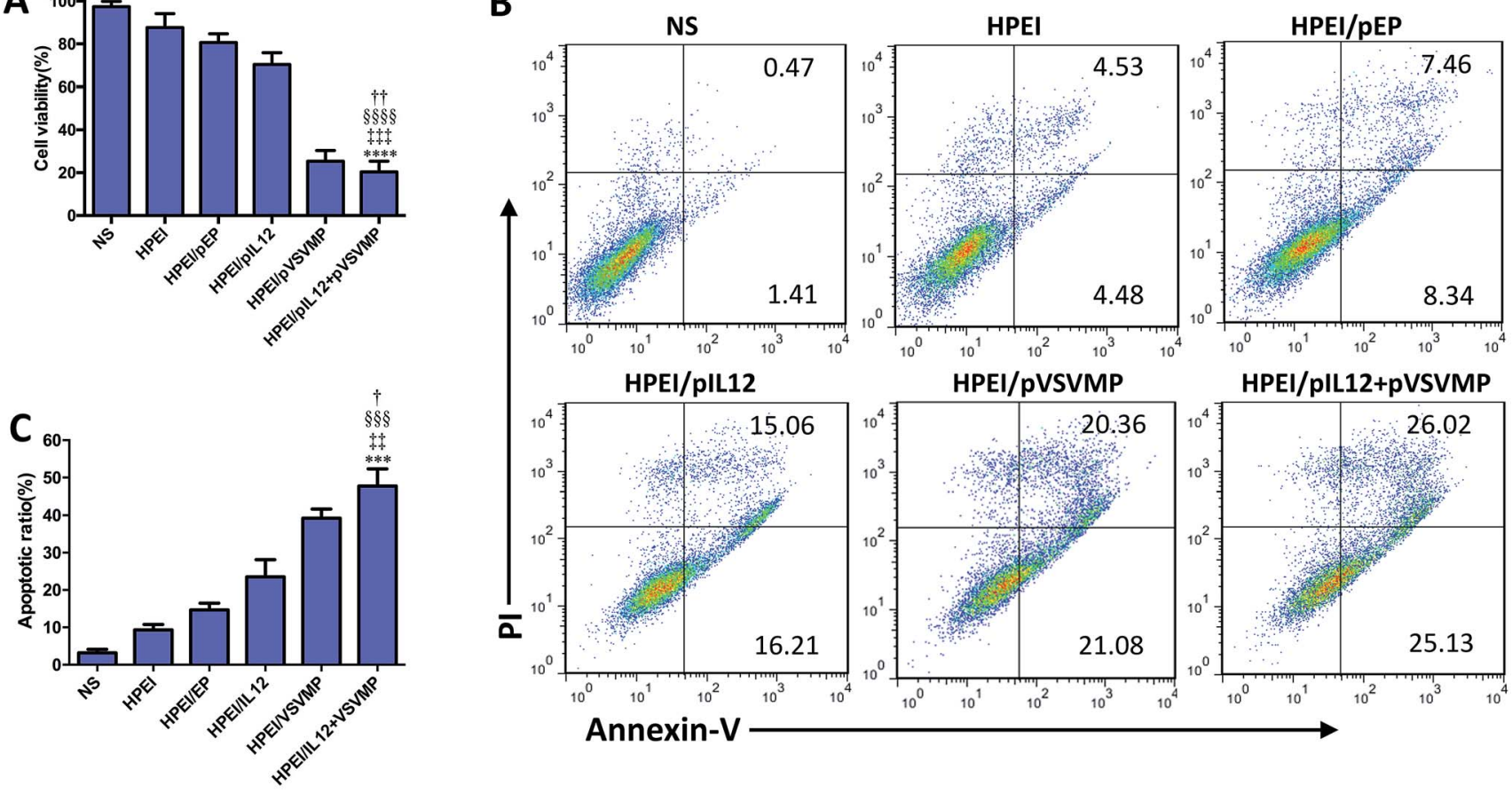

Fig. 4 Apoptosis induced by HPEI/pIL12 + pVSVMP complexes on C-26 cells in vitro. (A) Cell viability determined by MTT assay. (B and C) C-26 cells were treated with NS, HPEI alone, HPEI/EP, HPEI/pIL12, HPEI/pVSVMP or HPEI/pIL12 + pVSVMP complexes for $48 \mathrm{~h}$. Cells were then stained with propidium iodide and annexin- $V$ to evaluate apoptotic ratio by flow cytometric analysis. All data were representative of three independent

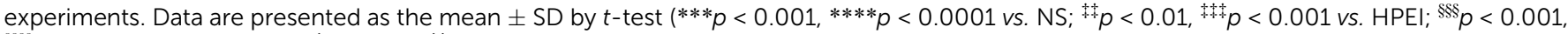
$\$ \$ \$ \$ p<0.0001$ vs. HPEI/pEP; ${ }^{\dagger} p<0.05,{ }^{\dagger \dagger} p<0.01$ vs. HPEI/pIL12). 

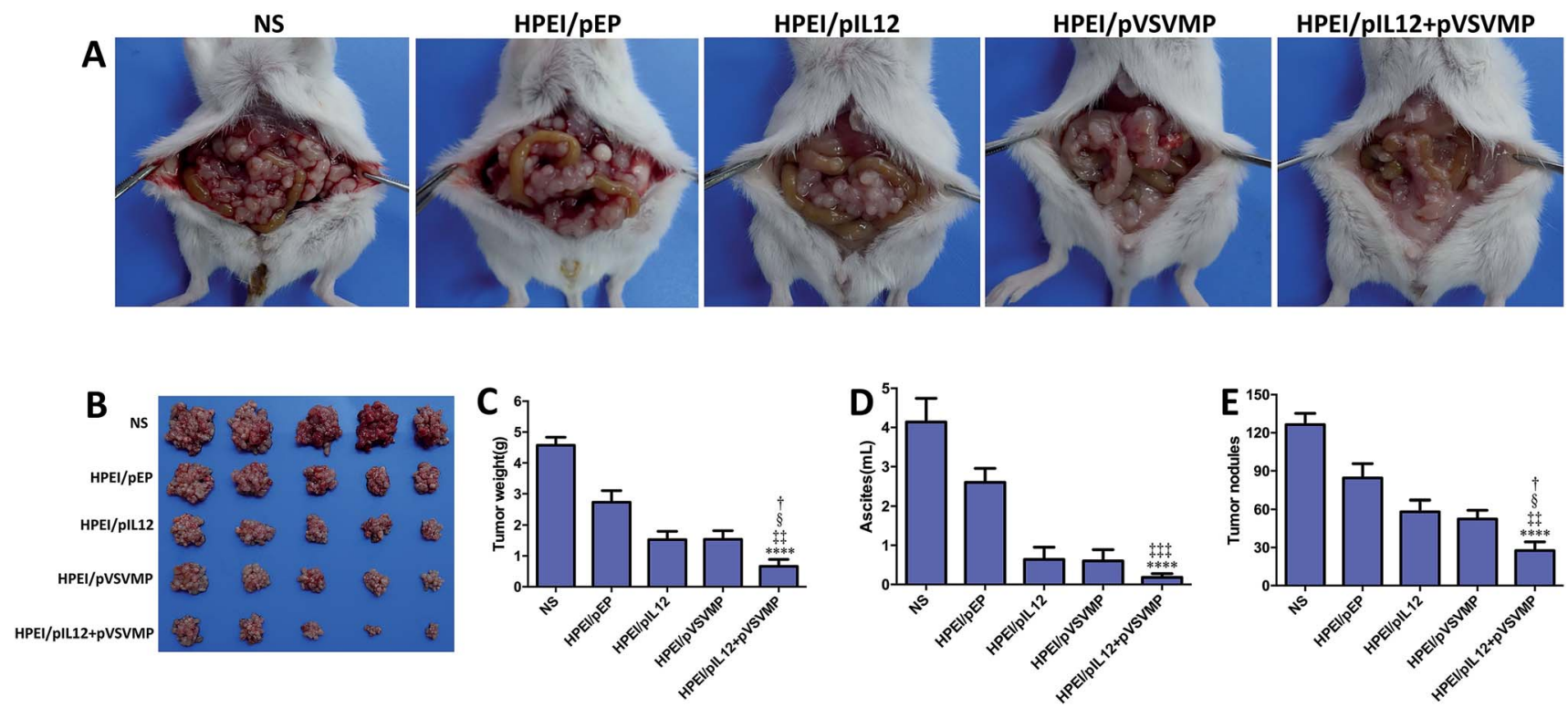

Fig. $5 \mathrm{HPEI} /$ plL12 + pVSVMP complexes inhibited the growth of abdominal metastases of C-26 colon cancer model in vivo. (A) Representative photographs of colon cancer in NS, HPEI/pEP, HPEI/pIL12, HPEI/pVSVMP or HPEI/pIL12 + pVSVMP complexes group, respectively. (B) Tumor images of each group. (C) The mean tumor weight of abdominal colon cancer metastasis. (D) Ascites volume. (E) Tumor nodules. All data were representative of three independent experiments. Data are presented as the mean \pm SD by $t$-test $(* * * * p<0.0001$ vs. NS; 柿 $p<0.01$, vs. HPEI/pEP; ${ }^{\S} p<0.05$ vs. HPEI/plL12; ${ }^{\dagger} p<0.05$ vs. HPEI/pVSVMP).

While the expression of VSVMP could be detected in HPEI/ pVSVMP complexes group and HPEI/pIL12 + pVSVMP complexes group (as shown in Fig. $3 \mathrm{E}, \mathrm{F}$ and $\mathrm{H}$ ). Then the viability of C-26 cells was determined by MTT assay and the results were presented in Fig. 4A. Co-delivery of pVSVMP and pIL12 by HPEI nanoparticles efficiently inhibited the viability of C-26 cells, while treatment with NS, HPEI complexes, HPEI/pEP complexes or HPEI/pIL12 complexes did not significantly
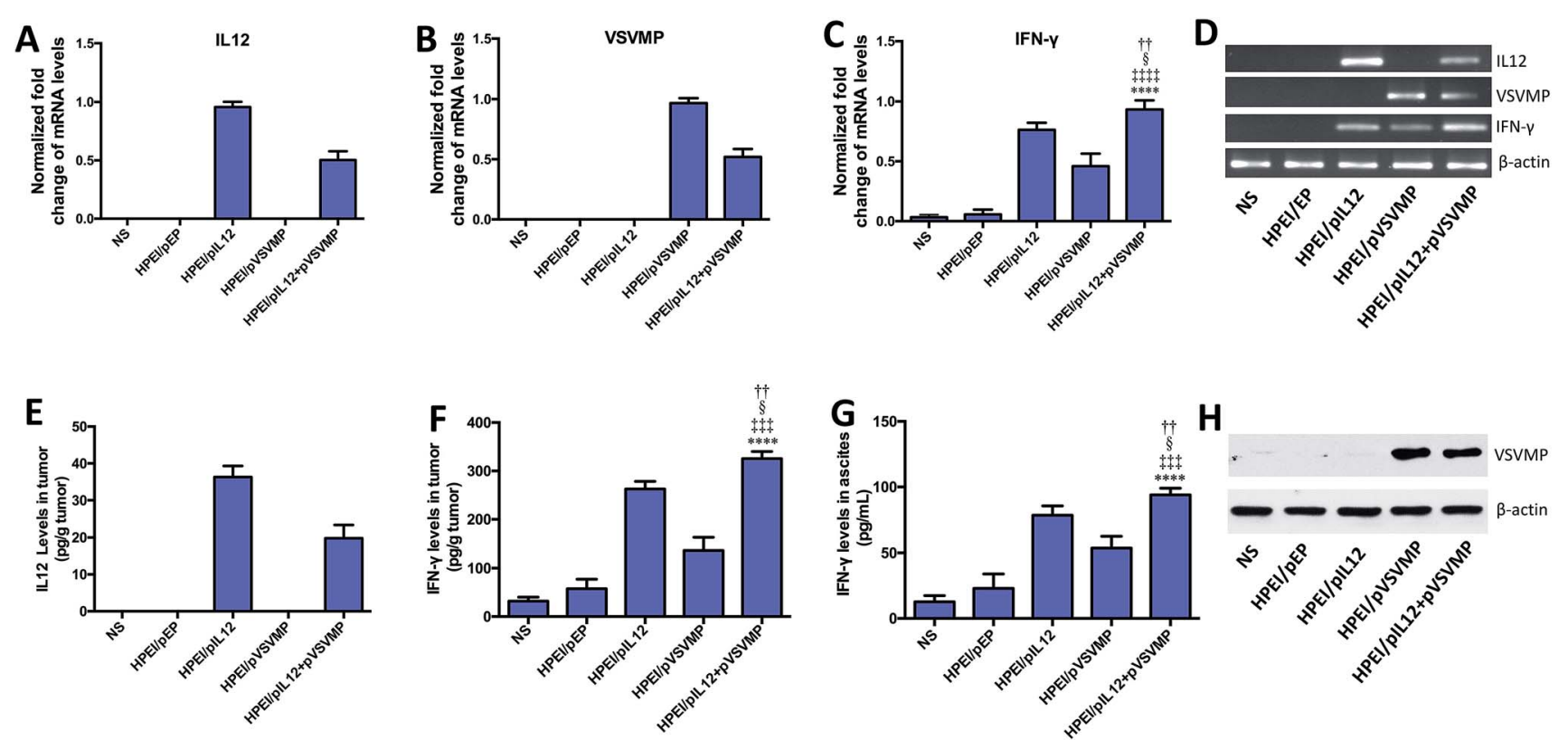

Fig. 6 Gene expression mediated by HPEI/pIL12 + pVSVMP complexes on C-26 colon cancer mice model. (A-D) Relative expression of IL12, VSVMP and IFN- $\gamma$ in each group were detected by real-time RT-PCR. (E) Expression of IL12 in tumor tissues was detected by ELISA assay. (F and G) Expression of IFN- $\gamma$ in tumor tissues and ascites were examined by ELISA assay. (H) Expression of VSVMP at the protein expression level were determined by western blot analysis. Data are presented as the mean \pm SD by $t$-test $\left(* * * * p<0.0001\right.$ vs. NS; ${ }^{* * t} p<0.001$, pEP; ${ }^{\S} p<0.05$ vs. HPEI/pIL12; ${ }^{\dagger} p<0.01$ vs. HPEI/pVSVMP). 
reduce cell viability. Those results implied that co-delivered VSVMP and IL12 by HPEI nanoparticles could efficiently inhibit the survival of C-26 colon cancer cells in vitro.

Furthermore, propidium iodide and annexin-V staining method was performed to reveal whether apoptosis was one of the main factors that contributed to the inhibition of C-26 colon cancer cells. As shown in Fig. $4 \mathrm{~B}$ and C, $47.7 \pm 7.5 \%$ of apoptotic cells were observed in response to the treatment with HPEI/ pIL12 + pVSVMP complexes $(10 \mu \mathrm{g}$ HPEI/1 $\mu \mathrm{g}$ pVSVMP $+1 \mu \mathrm{g}$ pIL12), $39.2 \pm 4.2 \%$ in HPEI/pVSVMP group $(10 \mu \mathrm{g} \mathrm{HPEI} / 2 \mu \mathrm{g}$ pVSVMP), $23.5 \pm 7.9 \%$ in HPEI/pIL12 group $(10 \mu \mathrm{g} \mathrm{HPEI} / 2 \mu \mathrm{g}$ pIL12), while $15.3 \pm 4.1 \%$ in HPEI/EP group $(10 \mu \mathrm{g} \mathrm{HPEI} / 2 \mu \mathrm{g}$ pEP), and only $9.3 \pm 2.4 \%$ were observed in the HPEI group (10 $\mu \mathrm{g}$ HPEI). These results suggested that the induction of apoptosis was associated with the anticancer effects of HPEI/ pIL12 + pVSVMP complexes mediated C-26 colon cancer gene therapy. However, the data in MTT-based cytotoxicity assay and $\mathrm{PI} /$ annexin-V based flow cytometric apoptosis assay suggested that there was no significant difference between HPEI/pVSVMP complexes and HPEI/pIL12 + pVSVMP complexes. The reason maybe in part due to the IL12 show strong antitumor effect by sensing innate and adaptive lymphocytes, ${ }^{\mathbf{4 6}, 47}$ rather than directly perform effective anti-cancer activity in vitro.

\section{Anticancer effect of HPEI/pIL12 + pVSVMP complexes in vivo}

To study the anticancer activity of HPEI/pIL12 + pVSVMP complexes on the abdominal cavity metastases of C-26 colon cancer, tumor-bearing mice were divided into five groups and treated with NS, HPEI/pEP complexes, HPEI/pIL12 complexes, HPEI/pVSVMP complexes and HPEI/pIL12 + pVSVMP complexes by intraperitoneal injection every two days. The metastatic tumor tissues in each group were harvested and weighed at day 17. As shown in Fig. 5A and B, the tumor progress was significantly inhibited in mice treated with HPEI/pIL12 + pVSVMP complexes compared with those treated with NS, HPEI/pEP complexes, HPEI/pIL12 complexes or HPEI/pVSVMP complexes. The average tumor weight in HPEI/pIL12 + pVSVMP complexes group was $(0.66 \pm 0.48) \mathrm{g}$, while it was $(4.57 \pm 0.57) \mathrm{g}$ in the NS group, $(2.75 \pm 0.82) \mathrm{g}$ in the HPEI/pEP

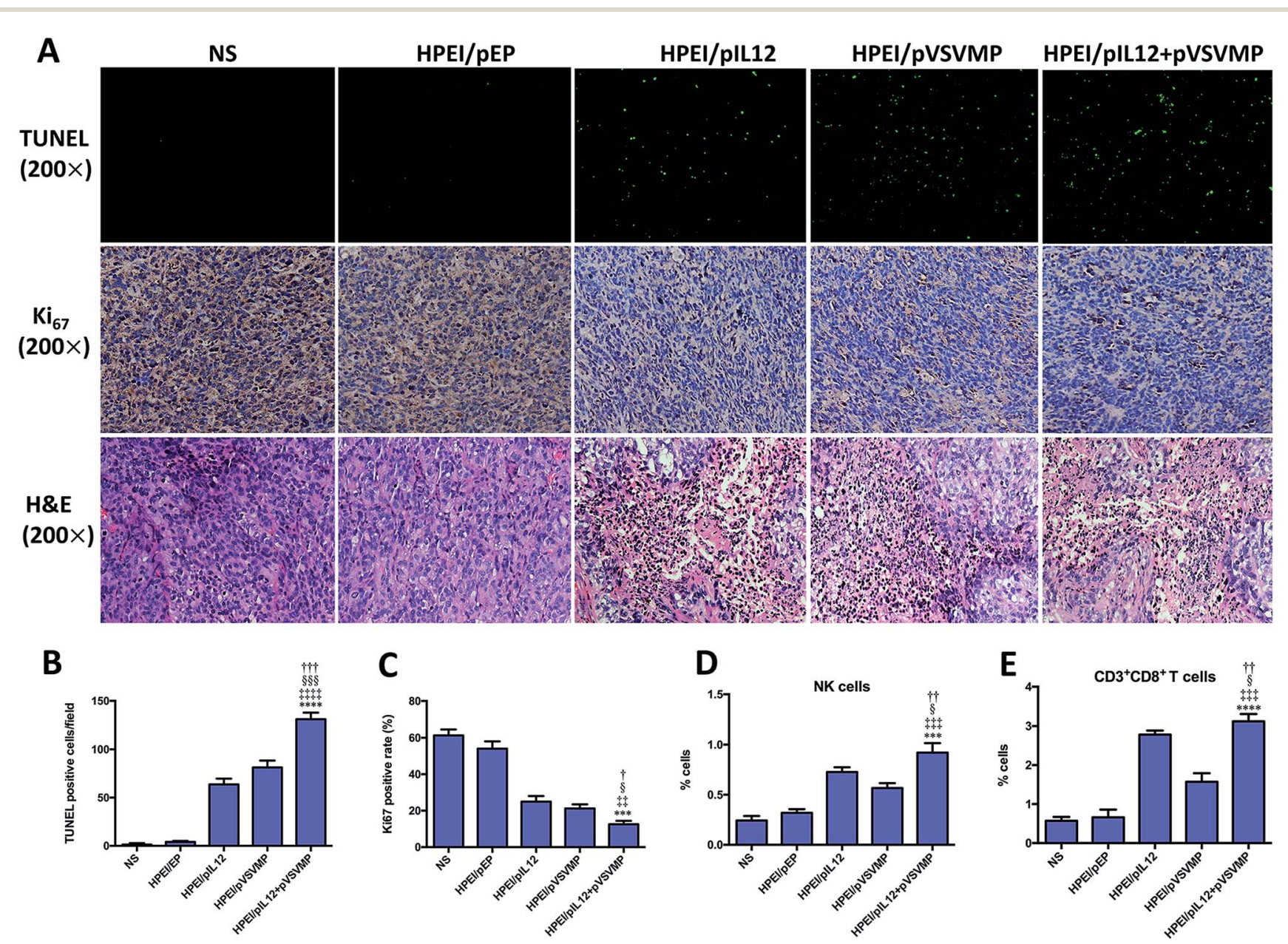

Fig. 7 Antitumor mechanisms of HPEI/pIL12 + pVSVMP complexes. (A) TUNEL assay, Ki ${ }_{67}$ staining and H\&E staining of the tumor tissues in each treatment group. (B and C) Tumor cell apoptosis and proliferation were assessed by counting the number of TUNEL-positive cells per field and the $\mathrm{Ki}_{67}$-positive rate (three high power fields per slide). (D) Splenic single cells were prepared and analyzed by flow cytometry for detecting activated NK cells. (E) Single-cell suspensions isolated from tumors were analyzed by flow cytometry for the presence of CD $8^{+} T$ cells. Data are

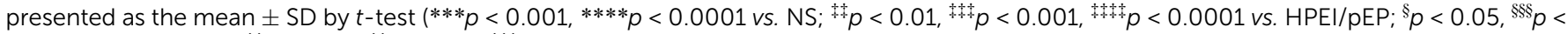
0.001 vs. HPEI/pIL12; ${ }^{\dagger \dagger} p<0.05,{ }^{\dagger \dagger} p<0.01,{ }^{\dagger \dagger} p<0.01$ vs. HPEI/pVSVMP). 
complexes group, $(1.54 \pm 0.59) \mathrm{g}$ in the HPEI/pIL12 complexes group, and $(1.52 \pm 0.62) \mathrm{g}$ in the HPEI/pVSVMP complexes group, respectively. It was obvious that the mice treated with HPEI/pIL12 + pVSVMP complexes showed a statistically significant reduction in tumor weight than other groups (Fig. 5C). Moreover, as shown in Fig. 5D, there was a statistically significant decrease in the ascites volume of the mice treated with HPEI/pIL12 + pVSVMP complexes $(0.21 \pm 0.18) \mathrm{mL}$, compared with $(4.14 \pm 1.35) \mathrm{mL}$ in the mice in the NS group, $(2.6 \pm 0.79)$ $\mathrm{mL}$ in the mice treated with HPEI/pEP complexes. In addition, compared with treatment with NS, HPEI/pEP complexes, HPEI/ pIL12 complexes or HPEI/pVSVMP complexes, treatment with HPEI/pIL12 + pVSVMP complexes also showed more efficiently inhibition in abdominal cavity metastases of C-26 colon carcinomas by reducing the number of tumor nodules from 125 to 28 (Fig. 5E). All these results suggested that HPEI/pIL12 + pVSVMP complexes exerted potent synergistic antitumor effects and significantly inhibited the growth of colon cancer cells in vivo.

Furthermore, we confirmed the expression of IL12 in tumor tissues by RT-PCR and ELISA. As shown in Fig. 6A, D and E. IL12 could be detected in mice treated with HPEI/pIL12 complexes or HPEI/pIL12 + pVSVMP complexes. We evaluated the expression of VSVMP by RT-PCR and western blot analysis, the results indicated that both HPEI/pVSVMP complexes and HPEI/pIL12 + pVSVMP complexes group had the expression of VSVMP (Fig. 6B and $\mathrm{H}$ ). Previous studies have demonstrated that IL12 stimulation could induce the secretion of IFN- $\gamma,{ }^{47,48}$ we further determined IFN- $\gamma$ level in tumor and ascites by RT-PCR and ELISA. As shown in Fig. 6C, D, F and G, the expression of IFN- $\gamma$ in tumor and ascites was significantly increased in mice treated with HPEI/pIL12 + pVSVMP complexes, compared with NS, HPEI/pEP complexes, HPEI/pIL12 complexes, or HPEI/pVSVMP complexes.

\section{Mechanisms underlying the anticancer effects of HPEI/pIL12 + pVSVMP complexes}

To explore the mechanisms involved in the anticancer activity of HPEI/pIL12 + pVSVMP complexes, tumor cell apoptosis and proliferation were examined. As shown in Fig. 7A and B, the TUNEL assay results revealed that significant increase of apoptosis positive cells was induced in tumor tissues treated with HPEI/pIL12 + pVSVMP complexes $(131.7 \pm 6.3)$ which was more than in those treated with NS $(1.5 \pm 1.2), \mathrm{HPEI} / \mathrm{pEP}$ complexes $(4.0 \pm 1.0), \mathrm{HPEI} / \mathrm{pIL} 12$ complexes $(63.6 \pm 6.5)$ or HPEI/pVSVMP complexes $(81.3 \pm 7.1)$. Moreover, the proliferation of tumor cells was analyzed by immune-histochemical staining for $\mathrm{Ki}_{67}$, a proliferation marker (Fig. $7 \mathrm{~A}$ and $\mathrm{C}$ ). Compared with NS $(61.3 \pm 3.2), \mathrm{HPEI} / \mathrm{pEP}$ complexes $(54.1 \pm$ 3.9), HPEI/pIL12 complexes $(24.3 \pm 3.1)$ or HPEI/pVSVMP complexes $(21.2 \pm 2.2)$, the percentage of $\mathrm{Ki}_{67}$ positive cells in the HPEI/pIL12 + pVSVMP complexes group $(12.5 \pm 1.9)$ was

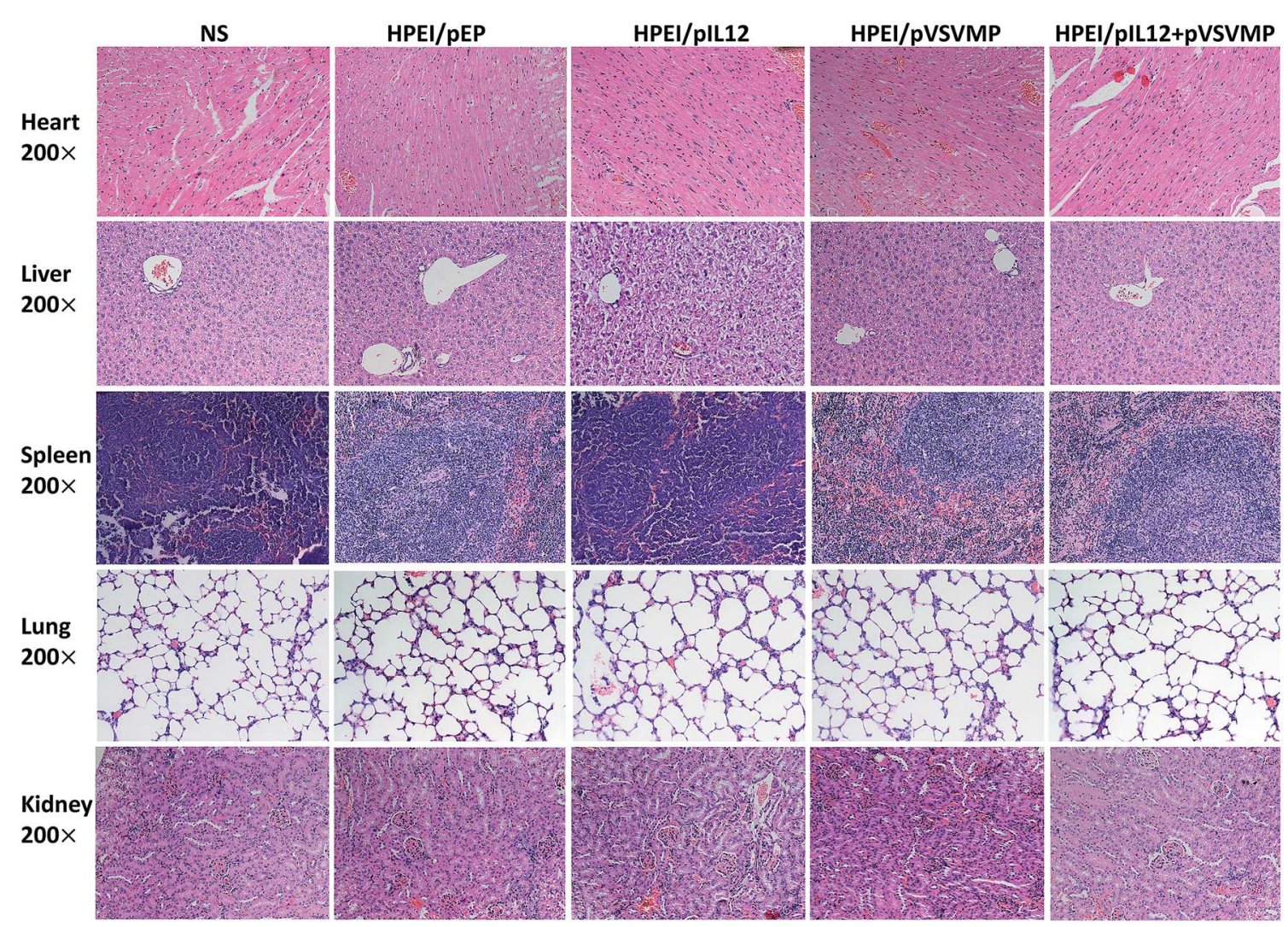

Fig. 8 Histological examinations of H\&E-stained vital organ sections. The heart, liver, spleen, lung, and kidney in NS, HPEI/pEP, HPEI/pIL12, HPEI/ pVSVMP or HPEI/pIL12 + pVSVMP complexes group were collected and conducted with HE staining, respectively. No significant pathological changes were detected. 
significant lower. H\&E staining of tumor sections indicated that there were more survival cancer cells in tumors treated with NS or HPEI/pEP. In contrast, tumor treated with HPEI/pIL12 complexes, HPEI/pVSVMP complexes or HPEI/pIL12 + pVSVMP complexes showed more dead cancer cells (Fig. 7A). Thus, the results suggested that the superior anticancer effects of HPEI/pIL12 + pVSVMP complexes may partly result from the induction of the tumor cells apoptosis and inhibition of tumor cells proliferation.

Moreover, quantifications of lymphocytes infiltration in spleen and tumor were performed by flow cytometry analysis. Two types of potential effector populations were stained with antibodies: PE-CD107a and FITC-CD49b (NK cells), FITC-CD3 and PE-CD8 $\left(\mathrm{CD}^{+} \mathrm{T}\right.$ cells). As shown in Fig. 7D, A higher ratio of activated NK cells from total spleen cells were detected in the HPEI/pIL12 + pVSVMP complexes group (0.92 $\pm 0.09 \%)$ than in the NS group $(0.24 \pm 0.05 \%)$, HPEI/pEP complexes group $(0.32 \pm 0.04 \%)$, HPEI/pIL12 complexes group $(0.72 \pm$ $0.05 \%)$ or $\mathrm{HPEI} / \mathrm{pVSVMP}$ complexes group $(0.57 \pm 0.06 \%)$. In addition, as shown in Fig. 7E, the percentage of $\mathrm{CD}^{+} \mathrm{T}$ cells in tumor was also dramatically increased in HPEI/pIL12 + pVSVMP complexes group $(3.05 \pm 0.23 \%)$, which was higher than in NS group $(0.57 \pm 0.10 \%), \mathrm{HPEI} / \mathrm{pEP}$ group $(0.66 \pm 0.19 \%), \mathrm{HPEI} /$ pIL12 group $(3.03 \pm 0.13 \%)$ or HPEI/pVSVMP group $(1.57 \pm$ $0.22 \%)$. These results are in line with that of other studies, ${ }^{\mathbf{1 9 , 2 0 , 4 6 , 4 7}}$ suggesting that HPEI/pIL12 + pVSVMP complexes treatment could enhance the activation of NK cells and $\mathrm{CD}^{+}{ }^{\mathrm{T}}$ cells compared with either treatment alone in vivo.

IL12 could activate both innate NK and $\mathrm{CD} 8^{+} \mathrm{T}$ cells, ${ }^{27,47,48}$ while VSVMP is capable of directly inducing tumor cell death. ${ }^{\mathbf{1 4 , 1 5}}$ Our data indicated that gene therapy with IL12 could enhance the antitumor effects of VSVMP. This synergistic antitumor effect of co-delivered IL12 and VSVMP by HPEI nanoparticles may result from induction of tumor cell apoptosis, inhibition of tumor cell proliferation, and activation of immune effector cells.

\section{HPEI/pIL12 + pVSVMP safety and toxicity assessment in mice}

To examine potential side effects of HPEI/pIL12 + pVSVMP complexes in mice. Some key mouse organs, including the heart, liver, spleen, lung and kidney, were harvested and performed H\&E staining for histopathological analysis. As shown in Fig. 8, no significant pathological changes were observed. Those results indicated that HPEI/pIL12 + pVSVMP complexes had no obvious toxic and side effects.

\section{Conclusions}

In summary, HPEI nanoparticles could co-bind pVSVMP and pIL12 through electrostatic interactions, and mediate the simultaneous expression of VSVMP and IL12 in colon cancer cells in vitro and in vivo. Intraperitoneal administration of HPEI/ pIL12 + pVSVMP complexes could efficiently inhibit the growth of intraperitoneal metastasis of C-26 colon cancer, showing synergistic anticancer effects, without obvious systemic adverse effects. This study suggested that VSVMP and IL12 could synergistically inhibit colon cancer, and the HPEI nanoparticle co-delivered VSVMP and IL12 might have potential application in treating intraperitoneal metastasis of colon cancer.

\section{Authors' contributions}

M. L. G. and Y. Y. X. conceived and designed the experiments. Y. Y. X., Y. P. Y., Y. J. W. analyzed the data. Y. Y. X., Y. P. Y., Y. J. W., C. M. W., H. C., W. Z., Y. L., J. L. L., W. H. G. performed the experiments. G. P. G. supervised the experiments. M. L. G. and Y. $Y$ Y. X. wrote the main manuscript text.

\section{Conflict of interest}

No potential conflicts of interest were disclosed.

\section{Acknowledgements}

This work was supported by the National Natural Science Foundation (81422025, 81572990), the Foundation for Distinguished Young Scientists of Sichuan Province (2016JQ0020), Sichuan province science and technology support plan (2015FZ0040, 2015SZ0049), and the Outstanding Young Scholars Research Fund of Sichuan University (2014SCU04A12).

\section{References}

1 C. E. DeSantis, R. L. Siegel, A. G. Sauer, K. D. Miller, S. A. Fedewa, K. I. Alcaraz and A. Jemal, Ca-Cancer J. Clin., 2016, 66, 290-308.

2 R. L. Siegel, K. D. Miller, S. A. Fedewa, D. J. Ahnen, R. G. S. Meester, A. Barzi and A. Jemal, Ca-Cancer J. Clin., 2017, 67, 177-193.

3 F. Ciardiello, Lancet Oncol., 2015, 16, 1444-1445.

4 A. R. Marley and H. Nan, Int. J. Mol. Epidemiol. Genet., 2016, 7, 105-114.

5 D. C. Damin and A. R. Lazzaron, World J. Gastroenterol., 2014, 20, 877-887.

6 U. T. Sankpal, G. P. Nagaraju, S. R. Gottipolu, M. Hurtado, C. G. Jordan, J. W. Simecka, M. Shoji, B. El-Rayes and R. Basha, Oncotarget, 2016, 7, 3186-3200.

7 J. Prados, C. Melguizo, H. Roldan, P. J. Alvarez, R. Ortiz, J. L. Arias and A. Aranega, BioDrugs, 2013, 27, 317-327.

8 H. Yin, R. L. Kanasty, A. A. Eltoukhy, A. J. Vegas, J. R. Dorkin and D. G. Anderson, Nat. Rev. Genet., 2014, 15, 541-555.

9 D. Ibraheem, A. Elaissari and H. Fessi, Int. J. Pharm., 2014, 459, 70-83.

10 I. M. Verma and N. Somia, Nature, 1997, 389, 239-242.

11 K. J. Kauffman, M. J. Webber and D. G. Anderson, J. Controlled Release, 2016, 240, 227-234.

12 M. Foldvari, D. W. Chen, N. Nafissi, D. Calderon, L. Narsineni and A. Rafiee, J. Controlled Release, 2016, 240, 165-190.

13 S. L. Ginn, I. E. Alexander, M. L. Edelstein, M. R. Abedi and J. Wixon, J. Gene Med., 2013, 15, 65-77.

14 S. A. Kopecky and D. S. Lyles, J. Virol., 2003, 77, 5524-5528. 15 D. F. Gaddy and D. S. Lyles, J. Virol., 2005, 79, 4170-4179. 
16 S. A. Kopecky and D. S. Lyles, J. Virol., 2003, 77, 4658-4669. 17 X. M. Jing, Y. J. Wen, W. Shi, Q. Q. Tang, J. Li and X. C. Chen, Cancer Gene Ther., 2012, 19, 101-109.

18 Q. Zhong, Y. J. Wen, H. S. Yang, H. Luo, A. F. Fu, F. Yang, L. J. Chen, X. Chen, X. R. Qi, H. G. Lin, Y. Wan, X. C. Chen, Y. Q. Wei and X. Zhao, Ann. Oncol., 2008, 19, 1584-1591.

19 J. M. Zhao, Y. J. Wen, Q. Li, Y. S. Wang, H. B. Wu, J. R. Xu, X. C. Chen, Y. Wu, L. Y. Fan, H. S. Yang, T. Liu, Z. Y. Ding, X. B. Du, P. Diao, J. Li, H. B. Wu, B. Kan, S. Lei, H. X. Deng, Y. Q. Mao, X. Zhao and Y. Q. Wei, FASEB J., 2008, 22, 4272-4280.

20 X. Lin, X. Chen, Y. Wei, J. Zhao, L. Fan, Y. Wen, H. Wu and X. Zhao, Gynecol. Oncol., 2007, 104, 540-546.

21 Z. Y. He, F. Deng, X. W. Wei, C. C. Ma, M. Luo, P. Zhang, Y. X. Sang, X. Liang, L. Liu, H. X. Qin, Y. L. Shen, T. Liu, Y. T. Liu, W. Wang, Y. J. Wen, X. Zhao, X. N. Zhang, Z. Y. Qian and Y. Q. Wei, Sci. Rep., 2016, 6, 23764.

22 S. Luo, P. Chen, Z. C. Luo, P. Zhang, P. Sun, W. Shi, Z. Y. Li, X. L. Zhang, L. Q. Wang, X. Chen, Y. Q. Wei and Y. J. Wen, Cancer Sci., 2010, 101, 1219-1225.

23 M. Gou, K. Men, J. Zhang, Y. Li, J. Song, S. Luo, H. Shi, Y. Wen, G. Guo, M. Huang, X. Zhao, Z. Qian and Y. Wei, ACS Nano, 2010, 4, 5573-5584.

24 W. Lasek, R. Zagozdzon and M. Jakobisiak, Cancer Immunol. Immunother., 2014, 63, 419-435.

25 M. L. Lucas, L. Heller, D. Coppola and R. Heller, Mol. Ther., 2002, 5, 668-675.

26 S. Li, X. Zhang and X. Xia, J. Natl. Cancer Inst., 2002, 94, 762768.

27 G. Trinchieri, Nat. Rev. Immunol., 2003, 3, 133-146.

28 T. Yue, X. Zheng, Y. Dou, X. Zheng, R. Sun, Z. Tian and H. Wei, BMC Cancer, 2016, 16, 665.

29 M. Ramamoorth and A. Narvekar, J. Clin. Diagn. Res., 2015, 9, GE01-GE06.

30 M. Neu, D. Fischer and T. Kissel, J. Gene Med., 2005, 7, 9921009.

31 U. Lungwitz, M. Breunig, T. Blunk and A. Gopferich, Eur. J. Pharm. Biopharm., 2005, 60, 247-266.
32 G. Liang, Y. Li, W. Feng, X. Wang, A. Jing, J. Li and K. Ma, Int. J. Nanomed., 2016, 11, 6079-6088.

33 H. K. Nguyen, P. Lemieux, S. V. Vinogradov, C. L. Gebhart, N. Guerin, G. Paradis, T. K. Bronich, V. Y. Alakhov and A. V. Kabanov, Gene Ther., 2000, 7, 126-138.

34 S. Gao, H. Tian, Z. Xing, D. Zhang, Y. Guo, Z. Guo, X. Zhu and X. Chen, J. Controlled Release, 2016, 243, 357-369.

35 P. Davoodi, M. P. Srinivasan and C. H. Wang, Acta Biomater., 2016, 39, 79-93.

36 M. A. Sheikh, Y. S. Malik, Z. Xing, Z. Guo, H. Tian, X. Zhu and X. Chen, Acta Biomater., 2017, 54, 58-68.

37 P. Liu, M. Gou, T. Yi, C. Xie, X. Qi, S. Zhou, H. Deng, Y. Wei and X. Zhao, Oncol. Rep., 2012, 27, 363-370.

38 F. Yang, M. Gou, H. Deng, T. Yi, Q. Zhong, Y. Wei and X. Zhao, Oncol. Rep., 2012, 28, 668-676.

39 Y. Xiong, Y. Zhao, L. Miao, C. M. Lin and L. Huang, J. Controlled Release, 2016, 244, 63-73.

40 X. Liang, B. Shi, K. Wang, M. Fan, D. Jiao, J. Ao, N. Song, C. Wang, J. Gu and Z. Li, Biomaterials, 2016, 82, 194-207.

41 P. A. Ascierto and F. M. Marincola, J. Transl. Med., 2011, 9, 115.

42 Y. Guo, W. He, S. Yang, D. Zhao, Z. Li and Y. Luan, Colloids Surf., B, 2016, 151, 119-127.

43 Y. Cui, M. Zhang, F. Zeng, H. Jin, Q. Xu and Y. Huang, ACS Appl. Mater. Interfaces, 2016, 8, 32159-32169.

44 L. Luo, T. Du, J. Zhang, W. Zhao, H. Cheng, Y. Yang, Y. Wu, C. Wang, K. Men and M. Gou, Int. J. Nanomed., 2016, 11, 501512.

45 A. Kawabata, A. Baoum, N. Ohta, S. Jacquez, G. M. Seo, C. Berkland and M. Tamura, Cancer Res., 2012, 72, 20572067.

46 R. Mortarini, A. Borri, G. Tragni, I. Bersani, C. Vegetti, E. Bajetta, S. Pilotti, V. Cerundolo and A. Anichini, Cancer Res., 2000, 60, 3559-3568.

47 K. S. Wang, D. A. Frank and J. Ritz, Blood, 2000, 95, 31833190.

48 S. X. Yang, W. S. Wei, Q. W. Ouyan, Q. H. Jiang, Y. F. Zou, W. Qu, J. H. Tu, Z. B. Zhou, H. L. Ding, C. W. Xie, Q. M. Lei and C. R. Zhong, Biomed. Pharmacother., 2016, 84, 1466-1471. 